\title{
Case Studies of Historical Epoch Shifts: Impacts on Space Systems and their Responses
}

\author{
J. Clark Beesemyer ${ }^{*}$, Adam M. Ross ${ }^{\dagger}$ and Donna H. Rhodes ${ }^{\ddagger}$ \\ Massachusetts Institute of Technology, Cambridge, MA, 02139
}

\begin{abstract}
Developing space systems often comes with high costs and long development times, resulting in significant investment. Space systems can take large amounts of resources to design, build, test, field, and operate, and can be required to operate for long periods of time in very harsh environments. These environments may be dynamic and possibly unanticipated during design and development. Given the large investment, space systems are expected to succeed in spite of encountering perturbations (disturbances or epoch shifts) that could impact their value delivery. The concept of value sustainment is proposed as the ability to maintain value delivery in the presence of such perturbations. Of the two types of perturbations, responses to epoch shifts (i.e. shift in context and/or needs) are investigated in this paper. The construct of Epoch Shift-Impact-Response-Outcome is proposed as a way to characterize and analyze historical system responses to changing operating contexts and needs. Four different historical cases, Iridium, Globalstar, Teledesic, and Galileo, and associated epoch shifts, are described, providing insights into how systems can respond to perturbations and what system characteristics aid in that process. The concept of ilities is briefly introduced, linking the system response to qualities that make a system successful. The epoch shift case studies, along with the corresponding displayed ilities in these systems, may provide a useful framework for future study. A broad survey of past systems characterized in this way may provide insights into the types of dynamic uncertainties that pose risks to such systems, as well as patterns of response (i.e. ilities) for such systems, in order to enhance the ability to intentionally design for value sustainment across dynamic operating environments in the future.
\end{abstract}

\section{Introduction}

$\mathrm{O}$ PERATING systems in space, with its associated "high-ground" perspective, enables capabilities otherwise not available or possible using terrestrial systems. Space provides an opportunity for platforms from which systems can affect lives on a global scale through enhancements to navigation and timing, communications, and remote imagery. These enhancements affect not only government agencies, but also civilian consumers as well, with such systems as GPS, imaging, satellite radio, and TV. While enabling the use of such technologies, the development and operation of space systems comes with a high cost. Manufacturing precision, experimental technology, international cooperation, vehicle launch, on-orbit operations, regulation compliance, and many other factors generate high risk and high costs for most space systems. These systems tend to be very complex and expensive, often operating in unforgiving environments for long periods of time. The impact of changes in these environments and the ability of a system to effectively respond to these changes could mean the difference between success and failure.

\section{Background}

From conceptual design through operations and finally decommissioning, systems are subjected to dynamic environments that may perturb the system's value delivery. Systems can use various means to counteract the effects

\footnotetext{
${ }^{*}$ Research Assistant, Aeronautics and Astronautics, MIT E38-555, 77 Massachusetts Ave.

${ }^{\dagger}$ Research Scientist, Engineering Systems Division, MIT E38-574, 77 Massachusetts Ave., and AIAA Senior Member.

${ }^{\ddagger}$ Principal Research Scientist, Engineering Systems Division, MIT E38-572, 77 Massachusetts Ave., and AIAA Member.
} 
of these perturbations, but the ultimate goal is to sustain value across disturbances or shifts. Distinguishing between the two types of perturbations, disturbances and epoch shifts, this research suggests two concepts for maintaining value across perturbations: in terms of value, systems should seek to survive disturbances and be robust to epoch shifts.

\section{A. Value Sustainment}

Sustaining value throughout dynamic environments motivates much of the research in engineering systems. Value sustainment is the ability to maintain value delivery in spite of perturbations ${ }^{1}$. Systems can use different strategies to respond to dynamic environments—systems can be designed to be robust to these changes or they can be designed to be changed to meet new needs. Perturbations are characterized into two types, shifts and disturbances, differentiated by the relative timescale of the system they affect and how long they act on the system ${ }^{1}$. This distinction is useful in that strategies dealing with disturbances in the short-term may differ from strategies dealing with shifts in the long-term.

\section{B. Changes in Context and Needs as Epochs and Eras}

Traditional systems engineering tends to focus on meeting technical requirements, as these are easier to verify and manage than non-technical uncertainties. However, failing to allocate enough time to proactively consider changes in requirements, or to account for non-technical uncertainties, may leave a system vulnerable in dynamic environments with changes occurring in both technical and nontechnical factors. This environment, or operational context of the system, and the set of stakeholder needs, can change over time. An "epoch" is a period of time, defined by a fixed set of context and needs, which impacts the ultimate success of a system ${ }^{2}$. A long-lived system may face a large number of epochs over its lifetime. Since the goal of any system is to meet its needs in various contexts, delivering benefit at cost—or value-across changing epochs is a measure of success as perceived by individual stakeholders of the system.

By the very nature of traditional acquisition phase-based lifecycles, system designers are required to make key design choices early in the system lifecycle that will impact the ultimate operational performance of the system in alternative future contexts, which may or may not match the original designed-for, anticipated context. A value robust system is one that maintains value delivery in spite of shifts in the system, contexts, or needs (epochs) ${ }^{3}$. These shifts in system, needs, or contexts are referred to as "epoch shifts." During its lifetime, a system may encounter multiple epochs in sequence, or an era, with a system's success depending on how well it responds to shifts across its lifecycle ${ }^{4}$, as seen in Fig. 1. Epoch-Era Analysis (EEA) is an approach for evaluating system alternatives across multiple epochs and eras.

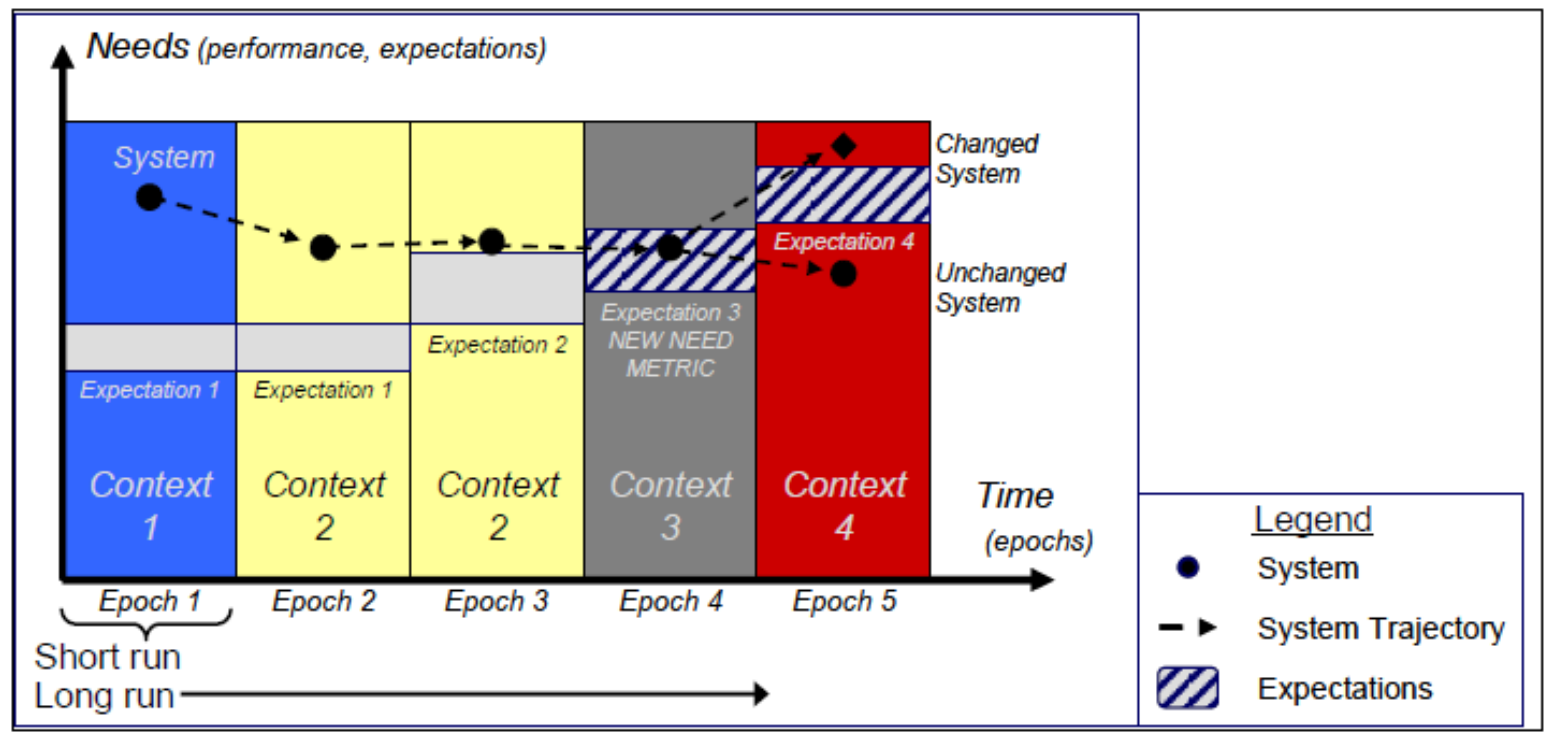

Figure 1. Epochs as short run, and eras as long run, system timelines ${ }^{2,4}$ 


\section{Survivability as a Means to Withstand Disturbances}

While a system can achieve value sustainment in the long run through value robustness, the short run value

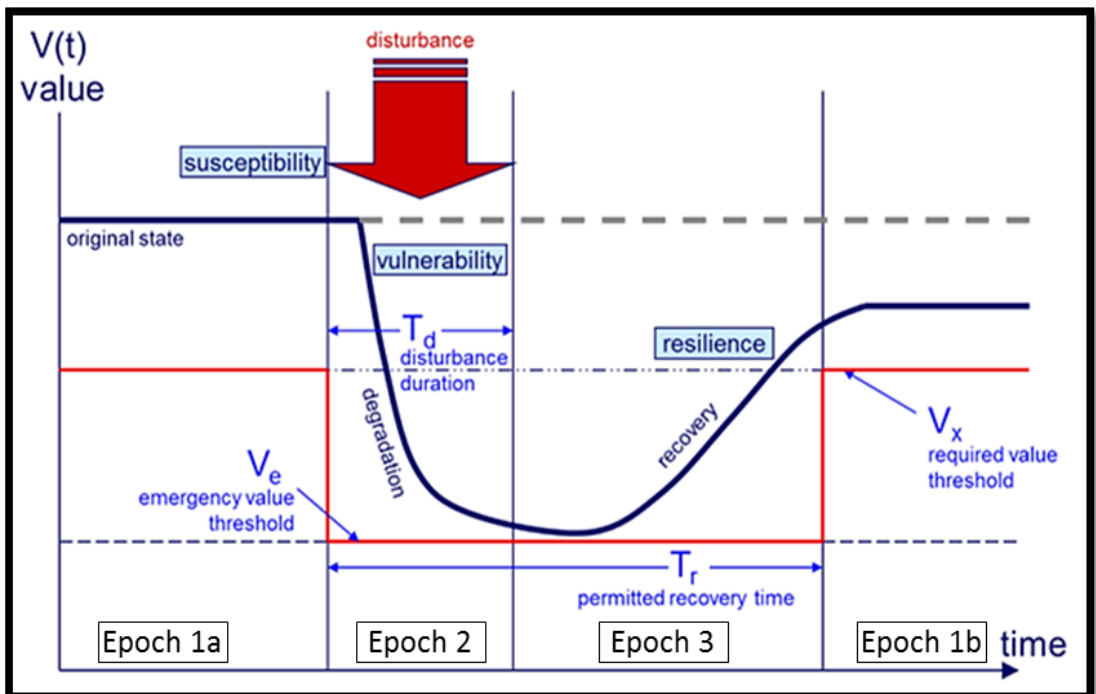

Figure 2. Definition of Survivability ${ }^{6}$ sustainment may be affected by disturbances to the system. Disturbances can be defined as unintended, finite duration changes of a system's form, operations, or context that could jeopardize value delivery ${ }^{5}$. Survivability (in "value"), then, is the ability of a system to minimize the impact of a (finite duration) disturbance on value delivery ${ }^{6,7}$.

Figure 2 shows three types of survivability; susceptibility reduction (Type I), vulnerability reduction (Type II), and resilience enhancement (Type III). Richards' survivability construct uses the idea of epochs ${ }^{2}$ to define the time periods around the disturbance. The idea being that after some disturbance, there is a return to the original epoch (i.e. the time period of the disturbance is short and the system environmental condition reverts to its prior state).

\section{Epoch Shift, Impact, Response, Outcome}

In developing a prescriptive approach for anticipating the impact of changing contexts and needs on systems, one may wish to investigate historical system examples for insight into how these systems responded to inevitable changes in their environment.

\section{A. The Construct}

Using a construct similar to the EpochEra Analysis representation presented above (Fig. 1), system case examples can be discussed using the Epoch shiftImpact-Response-Outcome construct as seen below in Fig. 3. The figure describes how a system may be operating at an acceptable level of performance in Epoch 1 and then experience an epoch shift. After experiencing this imposed shift in system, context, or needs, the system may display some degradation in performance, known as the impact, possibly bringing performance below acceptability levels. The system then, in order to recover to an acceptable performance level, may initiate a response, which then results in some outcome for the system. This construct is proposed and tested in the paper to determine feasibility of using such a construct for collecting and comparing historical systems for insights regarding the "success" of system responses relative to

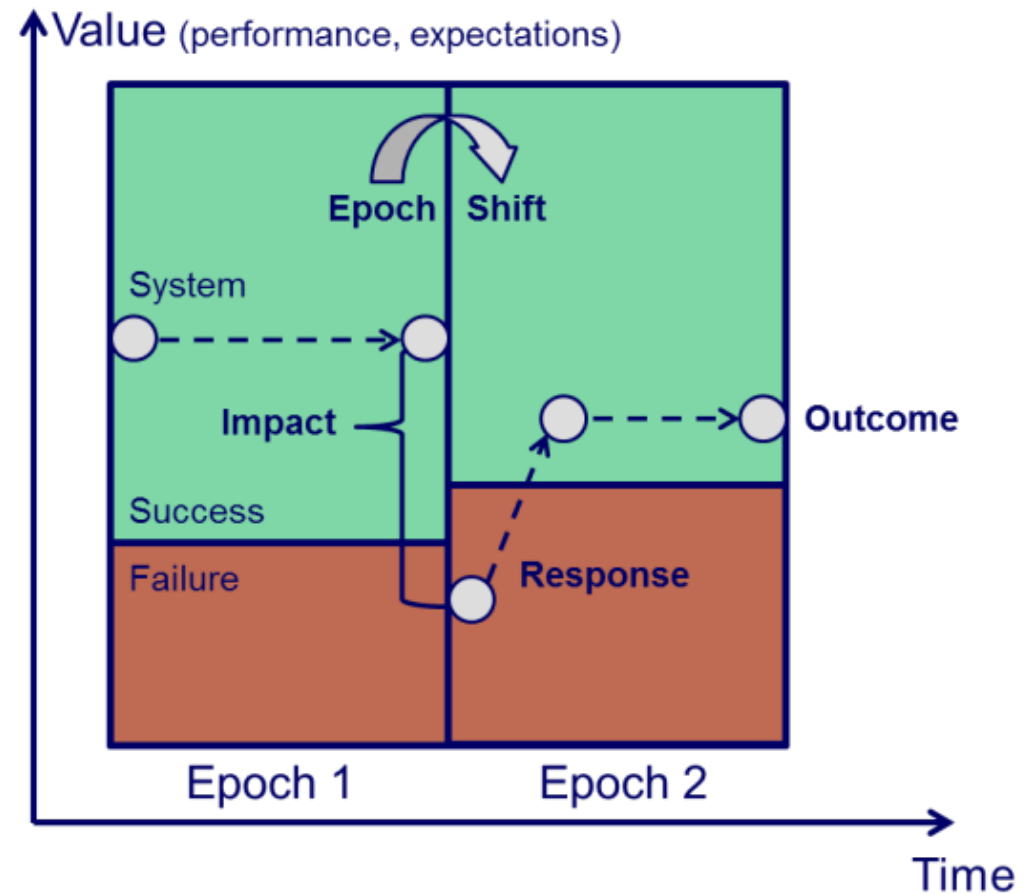

Figure 3. Epoch shift - Impact - Response - Outcome Construct

American Institute of Aeronautics and Astronautics 
epoch shifts, with the ultimate intention of providing prescriptive advice for new systems as a function of possible epoch shifts that the system may face over its lifetime.

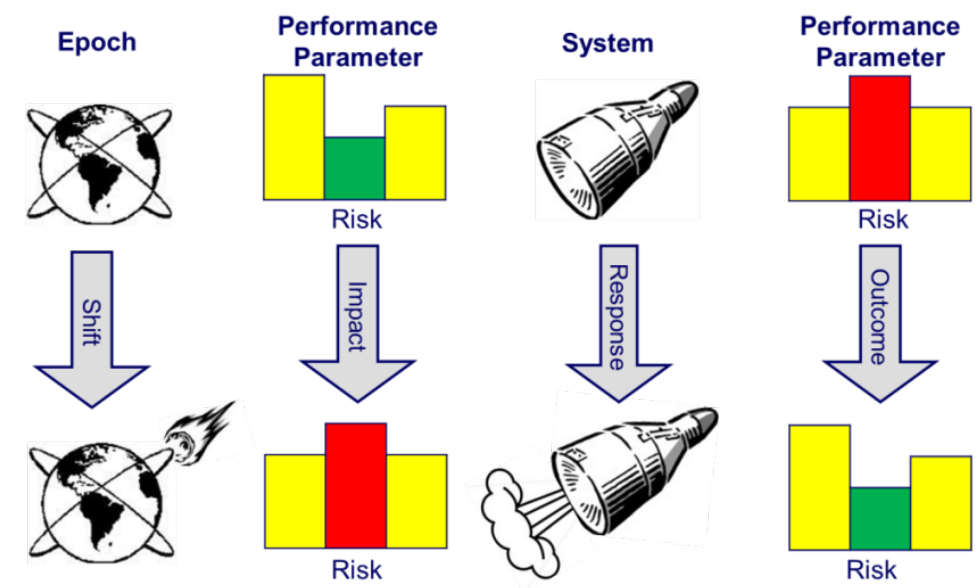

Figure 4. Simplified Epoch shift--Impact--Response-Outcome Example
A simplified example of this construct can be visualized as shown in Fig. 4. One can imagine a space environment in which a satellite is operating at expected performance levels. Some shift in context occurs, possibly the discovery of incoming debris outside of collision risk tolerances. This increase in risk impacts the performance of the system if stakeholders deem that risk unacceptable. System decision makers can choose to respond to this shift, possibly adjusting the orbit of the satellite by firing onboard thrusters. This change in orbital parameters may result in an outcome where the satellite is within acceptable risk levels, allowing the system to operate within stakeholder-defined expectations. If the satellite was unable to respond, it is possible the system could collide with the debris, resulting in a failure of the system. This is a simplified example just to illustrate the use of the construct.

\section{B. Types of Responses}

Value sustainment may be achieved by intentionally changing or not changing (remaining statically robust) the system in response to perturbations. It is important to see how systems that change in response to perturbations fit in with those that do not change, that is, those that remain statically robust and/or survivable.

One aspect that makes distinguishing between static systems - those systems that do not change-and dynamic systems - those systems that do change-difficult is whether one is talking about "change" relative to a system parameter or to the outcome parameter. Often when we think about robustness or survivability, the outcome parameter is the focus. In the case of value robustness, or value survivability, value is the outcome parameter that is targeted to remain above threshold values. The end user may not care how this robustness or survivability is achieved. The system can "change" in order to maintain a level of value, or it may "not change" to remain statically robust or survivable. To help visualize this relationship, Fig. 5 shows the two-by-two matrix of possible system parameter options and outcome parameter options ${ }^{1}$.

A system parameter will be some aspect of the system, form, function, or operations that relates to the design space, and is within the control of the designer. An outcome parameter can be either another system aspect or it can be some outcome attribute of the system, like performance or utility.

The labels placed in each of the quadrants are with respect to the outcome parameter. The most explicit label is changeability in quadrant one. If a system changes any of its parameters in order to achieve a change in an outcome parameter, then that transition is changeable. If a system does not have to change in order to achieve a change in outcome parameter, it is a versatile system (quadrant four). The left side of the matrix displays the survivable or

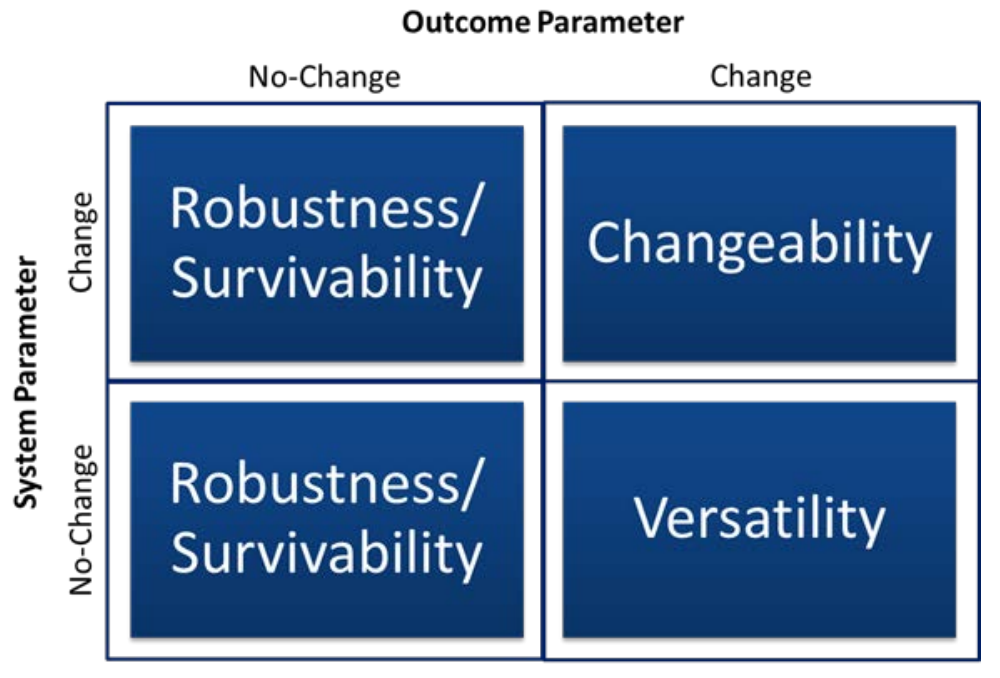

Figure 5. Typology of System Parameter vs. Outcome

Parameter Change or No-Change to Achieved Desired Quality in Outcome Parameter ${ }^{1}$

4

American Institute of Aeronautics and Astronautics 
robust designs that can either change or remain static in their system parameters to result in no-change of outcome parameters. The labels in both quadrants two and three are the same, "Robustness/ Survivability," since the only distinguisher is the type of perturbation under consideration.

In this way, systems that are static or dynamic in response to perturbations may be distinguished. Depending on how a system responds to various perturbations, different ilities may apply. Figure 5 shows a few of these highlevel ilities, but there are many more ilities that fall into one or more of the four main categories described above.

\section{Case Studies}

This section will present a set of historical space system examples of epoch shifts, the impacts of these shifts on the systems, the systems' responses, and the ultimate outcome of these responses on each system's success. The four cases detailed are from the Iridium, Globalstar, Teledesic, and Galileo space programs. These four systems represent distinct shifts and responses and were chosen for presentation for their varying outcomes. The epoch shifts within these cases will be described in terms of exogenous uncertainty. Responses to these shifts and patterns across the case studies will be studied to give insight on possible impacts from intentionally designing in the ability to respond to such shifts during system operations or earlier. Regarding the ability to respond, lifecycle properties, also known as "ilities", allow systems to react to potential epoch shifts during system design, implementation, or operations. The number of cases in this paper will help to consolidate historical examples of epoch shifts aiming to identify preliminary patterns of responses and impacts that may relate to ilities. These four cases may be used as proof of concept for the Epoch Shift - Impact - Response methodology and more systems could be examined in a similar manner.

\section{A. Iridium}

The Iridium story anecdotally began in 1985 when a Motorola engineer's wife complained about an inability to reach clients while vacationing in the Caribbean ${ }^{8}$. In short time, Motorola announced this new concept for Iridium as "a global communications system that will allow people to communicate by telephone anywhere on Earth whether on land, at sea or in the air - via portable cellular radiotelephones operating as part of a satellite-based system,", . Numerous companies, including Motorola, Kyocera, Lockheed Martin, and Raytheon, helped to design and develop the Iridium system. The system attempted to make space communications viable by using Low-EarthOrbiting (LEO) satellites (allowing for smaller handsets and no voice delay compared to Geostationary EarthOrbiting (GEO) satellites).

Almost a decade after the concept of the system was envisioned, detailed design of the Iridium system took place. The system itself is comprised of 66 cross-linked satellites (plus 6 in-orbit spares) at a $778 \mathrm{~km}$ altitude in 6 polar planes with 11 satellites in each. Iridium represented one of the biggest technical achievements in space communications in the 1990's, delivering more than 1,000 patents ${ }^{8}$. The system includes inter-sat links, ground control facilities, terrestrial Earth gateways (to interconnect with telephone networks), and the actual mobile phones and pagers ${ }^{9}$. By 1998, when the system became operational, the system had cost over $\$ 5$ billion to build and maintain $^{8}$.

Iridium, as a company, was represented by very strong top leadership and engineering teams, and was focused on solving many of the technical requirements of getting a LEO communication constellation to function properly ${ }^{8}$. In 1998, the company started a \$180 million marketing campaign and even had Vice President Al Gore make the first Iridium phone call. The company commenced commercial operations with a $\$ 3,000$ handset cost and \$3-\$8 per minute calls and the results were devastating. After two quarters, the company had only 10,000 subscribers, and only 20,000 subscribers almost a year into operations, far less than the projected 500,000 users. The company needed 52,000 customers to meet loan interest payments and was unable to make necessary payments, defaulting on $\$ 1.5$ billion in loans. On August 13, 1999, Iridium filed for Chapter 11 bankruptcy and became one of the 20 largest bankruptcies in U.S. history ${ }^{8}$.

The company, planning to de-orbit the satellites, instead sold and restructured the company for just $\$ 25$ million and became Iridium LLC. Iridium ended up selling for just about $1 / 2$ a percent of the initial investment, and began new operations with $\$ 72$ million Department of Defense (DoD) contract $^{10}$. It has been argued that the company failed due to three main reasons ${ }^{8}$ :

1. An escalating commitment, particularly among Motorola executives who pushed the project forward in spite of known potentially fatal market and technological problems.

2. Iridium CEO's reluctance to cut losses and abandon the project due personal and professional reasons.

3. The Iridium board structure that prevented it from performing its role of corporate governance. 
A highlighted flaw in this report is the fact that Iridium executives knew about the risks in the market. A 1998 prospectus listed 25 full pages of risks including ${ }^{8}$ :

- $\quad$ a highly leveraged capital structure

- design limitations - including phone size

- $\quad$ service limitations - including severe degradation in cars, buildings, and urban areas

- high handset and service pricing

- the build-out of cellular networks

- a lack of control over partners' marketing efforts

Evidence shows that even though Motorola knew about these risks, no effort was effectively made to address or mitigate these risks. The belief that the innovative technological advances of the system would carry the company did not come to fruition. While the company saw lots of hype and excited initial investors, its launch was underwhelming, put best by CEO John Richardson:

"We're a classic MBA case study in how not to introduce a product. First, we created a marvelous technological achievement. Then we asked how to make money on it." - Iridium Interim CEO John A. Richardson, August $1999^{8}$

The company had miscalculated the terrestrial cellular network development throughout Iridium's design and testing in the 1990s. The potential customers began to value small handsets, coverage indoors and in cars, and reasonable prices. The Iridium handset was costly, large and heavy, and it did not work well indoors or in cars.

Applying this case to the Epoch shift-Impact-Response-Outcome construct we can characterize these events in a structured manner. The epoch shift the company undergoes is a gradual shift from the conception of the system in 1985 through its design in the 1990's. The system began in a context where there was a need for global communications from a portable handset with limited voice delays. This context did not include a developed terrestrial cellular infrastructure. Throughout the 1990's, the need for global communication did not change, in fact it increased. However, with increasing terrestrial cellular developments, consumers' needs shifted to lighter, affordable devices that could work everywhere, including indoors and in cars. This impacted Iridium by moving the system into an unaffordable, too heavy, non-functional (indoors and in cars) performance space from the perspective of consumers. Iridium responded to this impact by continuing with original plans, not changing much at all. Iridium launched the complete constellation and initiated service with $\$ 3,000$ handsets that were large and heavy and cost about \$3-8 per minute to operate. The outcome Iridium experienced was a lack of user subscriptions, defaulting on loan commitments, and the ultimate bankruptcy of the company and possible de-orbiting of the constellation. Either this characterization shows how Iridium miscalculated the impact of the epoch shift, resulting in an improper response, or they may have understood the impact correctly, but simply did not respond in an effective manner. This Epoch shift-Impact—Response-Outcome characterization is summarized in a snapshot in Fig. 5 below. 


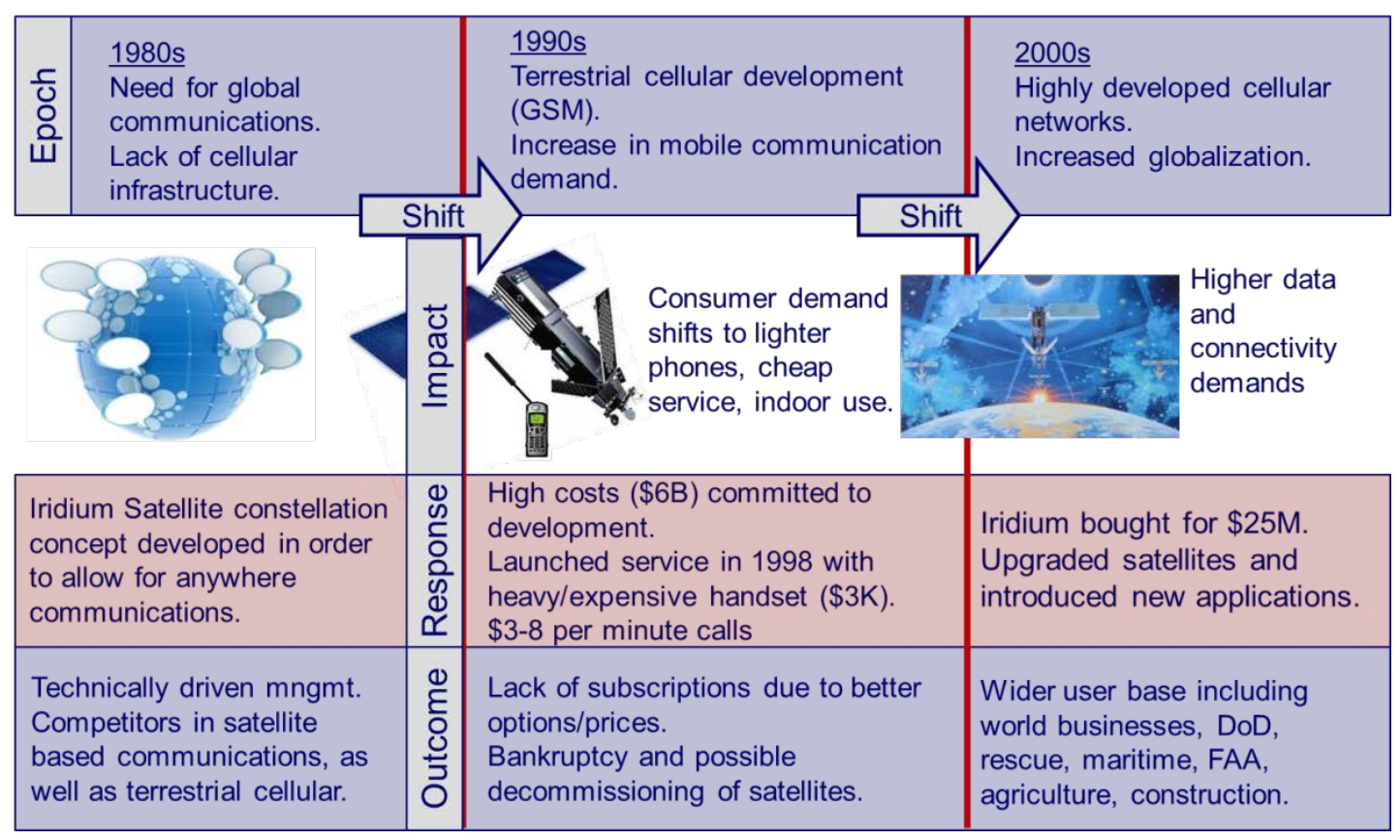

Figure 6. Iridium Epoch shift--Impact--Response--Outcome Snapshot

The aftermath of Iridium however did not involve the decommissioning of the constellation. The company underwent another epoch shift and was able to respond in a way that allowed it to continue operations. The context of the system had shifted in the 2000's to highly developed cellular networks and an even larger amount of globalization and world communications in not just voice, but data as well. Following the events of September 11, 2001, increased emphasis on tracking trans-oceanic airplanes as well as in-flight data services allowed for new markets in which Iridium could compete. This impacted the system by increasing the data and connectivity demands in the market in areas terrestrial cellular systems could not reach. Iridium responded to these shifts first by selling and restructuring for \$25 million, finding new customers, including the FAA and DoD, and upgrading satellites to introduce new functions. New functions include airplane guidance over oceans and poles, airplane black-box data collection and storage, remote location services (e.g. construction, oil rigs, foresting), military communications, and emergency response efforts ${ }^{11}$. This resulted in a positive outcome for Iridium—a successful system operating in the green with increased commercial subscriptions (450,000 subscribers as of March 2011) and other contracts like the DoD. The company is preparing for its next response to the currently shifting context with a new constellation of IridiumNEXT satellites in 2015, with increased functionality, higher data speeds and new services in Enterprise data and voice, asset tracking, and other machine-to-machine applications. Time will tell if this response is too delayed or appropriate for the current context.

\section{B. Globalstar}

The story of Globalstar is similar to that of Iridium ${ }^{12}$. Funded primarily by Qualcomm Inc. and Loral Space \& Communications, Globalstar was designed to provide global space-based communications including voice, data, fax, paging, and positioning ${ }^{13}$.

Globalstar implemented a 48 LEO satellite constellation (4 spare) at a $1414 \mathrm{~km}$ altitude in 8 polar planes with 6 satellites in each. Similarly to Iridium, Globalstar implements terrestrial gateways to link satellites to telephone networks. However, in order to simplify in-orbit satellites, Globalstar does not use on-board inter-satellite switching links (ISL), requiring more earth gateways to interconnect with telephone networks. Unlike Iridium, processing occurs on the ground, in an effort to make a more affordable system. Satellites act as simple signal repeaters, known as a "bent-pipe" architecture ${ }^{13}$. 


\begin{tabular}{|c|c|c|c|c|}
\hline \multirow[t]{2}{*}{$\begin{array}{l}\text { 등 } \\
\text { 유 }\end{array}$} & \multicolumn{2}{|l|}{$\begin{array}{l}\frac{1980 \mathrm{~s}}{\text { Need for global }} \\
\text { communications. } \\
\text { Complex Iridium concept. } \\
\text { Lack of cellular } \\
\text { infrastructure. }\end{array}$} & $\begin{array}{l}\text { 1990s } \\
\text { Cellular development (GSM). } \\
\text { Consumer demand shifts to } \\
\text { lighter phones, cheap service, } \\
\text { indoor use. } \\
\text { Iridium bankruptcy. }\end{array}$ & $\begin{array}{l}\underline{2000 s} \\
\text { Highly developed cellular } \\
\text { networks. Higher data } \\
\text { demands. } \\
\text { Increased globalization. } \\
\text { Increased DoD usage (war) }\end{array}$ \\
\hline & & 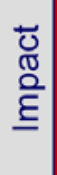 & $\begin{array}{l}\text { Consumer demand } \\
\text { shifts to lighter }\end{array}$ & \begin{tabular}{l|l} 
& $\begin{array}{l}\text { Higher data } \\
\text { and } \\
\text { Launching } \\
\text { the future. }\end{array}$ \\
connectivity \\
demands
\end{tabular} \\
\hline \multicolumn{2}{|c|}{$\begin{array}{l}\text { Globalstar constellation } \\
\text { concept to use higher, } \\
\text { lighter sats, no ISL. } \\
\text { Target developing nations. }\end{array}$} & 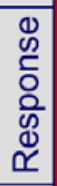 & $\begin{array}{l}\text { High costs }(\$ 3.8 \mathrm{~B}) \text { committed to } \\
\text { development. } \\
\text { Launched service in } 2000 \text {. } \\
\text { Handset }(\$ 1 \mathrm{~K}) \text { heavy/expensive } \\
\$ 1-3 \text { per minute calls }\end{array}$ & $\begin{array}{l}\text { Globalstar bought for } \$ 45 \mathrm{M} \text {. } \\
\text { Upgrading satellites, improving } \\
\text { service } \\
\text { Lower cost to } \$ 1 \text { per minute w/ } \\
\text { specials for calling home (US) }\end{array}$ \\
\hline \multicolumn{2}{|c|}{$\begin{array}{l}\text { Competitors in satellite } \\
\text { based communications, as } \\
\text { well as terrestrial cellular } \\
\text { contending for market. }\end{array}$} & 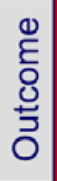 & $\begin{array}{l}\text { Lack of subscriptions due to better } \\
\text { options/prices in cellular. } \\
\text { Cheaper than Iridium but market } \\
\text { cleared out following Iridium failure. } \\
\text { Bankruptcy. }\end{array}$ & $\begin{array}{l}\text { Wider user base including rural } \\
\text { areas, DoD, travelers, } \\
\text { maritime, developing nations. }\end{array}$ \\
\hline
\end{tabular}

Figure 7. Globalstar Epoch shift-Impact-Response-Outcome Snapshot

Globalstar required \$3.8 billion to build and maintain by 2000 when it became commercially operational. Service commenced with a $\$ 1,000$ handset cost and \$1-\$3 per minute calls. Globalstar attempted to avoid Iridium's fate by appealing to broader target markets with a more aggressive marketing campaign while lowering costs and usage fees. However, like Iridium, Globalstar projected more potential users than what was realized. Globalstar filed for bankruptcy for $\$ 3.3$ billion in 2002. Like Iridium, Globalstar was able to restructure and capitalize on niche markets to allow the system to survive, albeit with less users than expected. Both Iridium and Globalstar suffered an initial failure, ending in bankruptcy; however both systems also lived on in the end, with bankruptcy allowing the systems to be salvaged and continue to deliver value ${ }^{13}$.

In this case, the epoch shifts were similar to those in the Iridium case. The responses were different however. Globalstar attempted to cut costs by altering the architecture, requiring more ground gateways, with fewer and less complex satellites in the constellation. Despite these efforts however, the company was not able to gain enough subscribers to cover the still high costs of system development. In the end, Globalstar suffered the same outcomes as Iridium $^{12}$, an initial business failure, followed by a bankruptcy-permitted rebirth and restructuring. In Fig. 6, the Globalstar Epoch shift—Impact—Response-Outcome is summarized in a snapshot figure.

\section{Teledesic}

One of the most ambitious satellite communication systems ever planned was Teledesic in the early 1990s, a $\$ 9$ billion (in 1995 dollars) space-based internet provider ${ }^{14}$. It was proposed as the "Internet in the Sky," and aimed to provide the ability to send and receive information anywhere on the face of the planet. Numerous telecommunication companies displayed interest in such a system, including Craig McCraw of AT\&T, Bill Gates of Microsoft, and Prince Alwaleed Bin Talal Bin Abdulaziz of Saudi Arabia. The company was able to raise $\$ 1$ billion before the Iridium failure showed signs of declining market for LEO communication satellites ${ }^{15}$.

Teledesic originally planned for 840 LEO satellites at a $700 \mathrm{~km}$ altitude with 21 orbital planes containing 40 satellites per plane. It planned for complex inter-satellite switching links (ISL), as well as terrestrial gateway links, mobile links, and terminal links ${ }^{14}$.

In 1997, Teledesic scaled its large constellation down to 288 satellites at a higher $1400 \mathrm{~km}$ altitude with 12 orbital planes containing 24 satellites in each plane ${ }^{14}$. Later, Teledesic further scaled down to 30 satellites as market demand continued to decrease. 
While Teledesic did manage to build and launch one test satellite in 1998, the company ended up releasing its frequencies and ceased work in 2003. While Teledesic did lose money, and ultimately did not become a viable system, unable to be robust to shifts in context, it was wisely shut-down, minimizing excessive downsides costs.

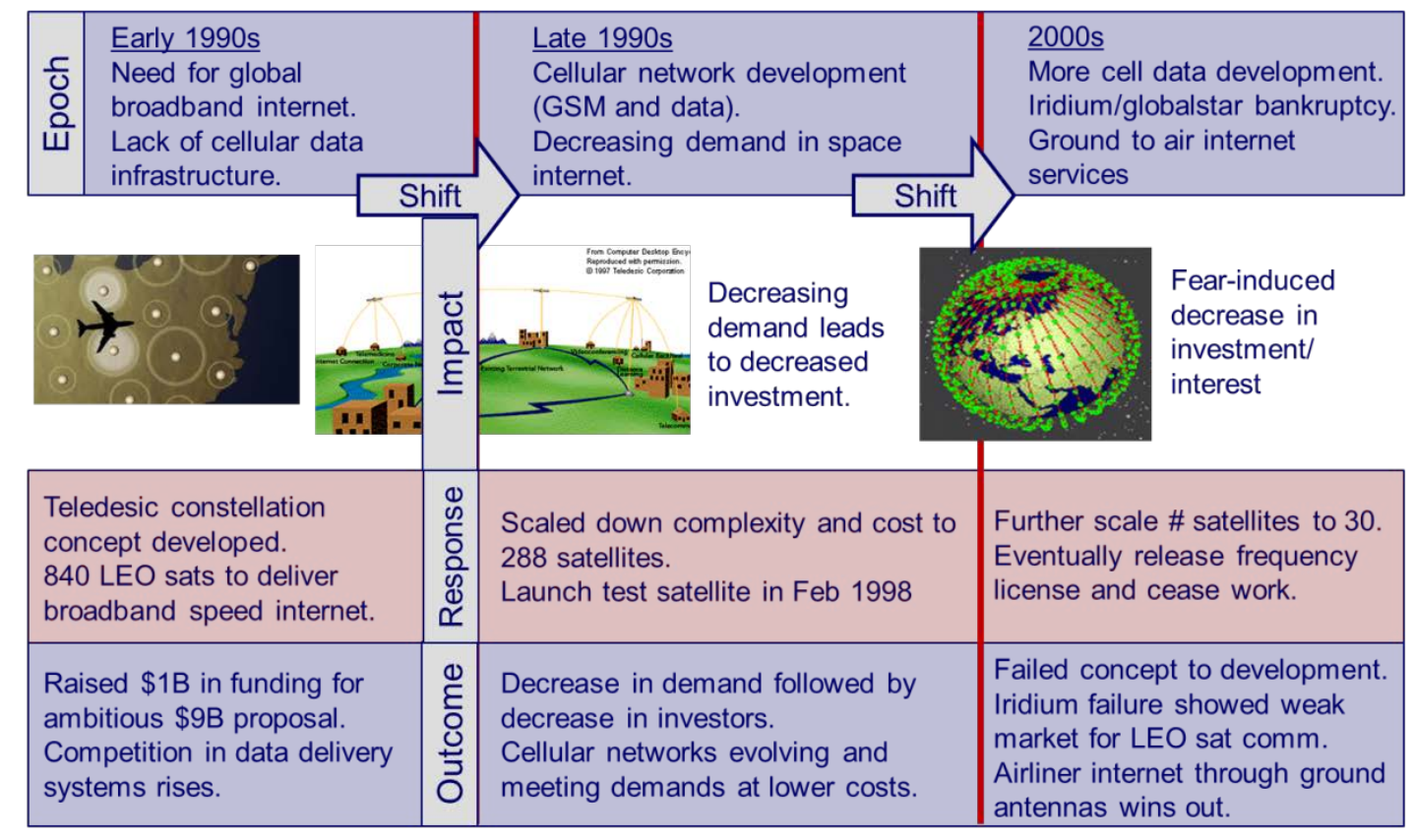

Figure 8. Teledesic Epoch shift-Impact-Response-Outcome Snapshot

This system had the benefit to see other systems fail, like Iridium and Globalstar, and used that information to respond to the shift in market needs. The de Neufville and Scholtes (2011) point of view might argue that the Teledesic response displays flexibility in that the system was able to minimize possible downsides as market uncertainty unfolded ${ }^{10}$. Since the system would require a full constellation to provide internet for the first user, the system could not capitalize on any staged-deployment strategies ${ }^{12}$. In Fig. 7, the Teledesic Epoch shift—ImpactResponse-Outcome is summarized in a snapshot figure.

\section{Galileo}

Galileo was a National Aeronautics and Space Administration (NASA) satellite built to explore Jupiter and its moons ${ }^{16,17}$. The satellite initially was intended for launch aboard a space shuttle in 1985, but due to launch delays and the 1986 Challenger disaster, the mission did not launch until 1989 aboard space shuttle Atlantis. This new launch meant that the satellite spent a lot of time waiting, and would have to wait even longer to reach Jupiter by taking a slower, less direct route to its final destination.

The Galileo satellite was a $\$ 1.4$ billion space probe that relied heavily upon its ability to deploy its high gain antenna, its primary payload that would be used to relay data and images back to Earth. In 1991 however, during the 6 year transit to Jupiter, the antenna failed to deploy and was stuck in a closed and dysfunctional position, severely limiting capabilities of data communications. The reasons for this failure are not definitively known , but it is speculated that the long time spent on the shelf waiting for launch resulted in dried lubricants. It was feared that if the satellite could not deploy this antenna, the mission would be a failure. Efforts to open the antenna over the rest of the travel time to Jupiter failed, so extensive flight and ground software modifications were made in order to use a lower-powered antenna on the satellite as a substitution. Additionally, modifications were made to NASA's Deep Space Network to make up for the performance loss of Galileo's transmission capabilities. In the end, the satellite was able to achieve at least $70 \%$ of its original science mission objectives and some unplanned ones as well ${ }^{16}$.

Later in its mission, after much time spent in a harsh radiation environment, the satellite suffered other anomalies in system components. Since the transmission of images back to Earth took so much longer with the weaker antenna, recording and storing the data became more of an issue. Due to the new need of increased data storage while slowly transmitting it back to Earth, Galileo's tape recorder became even more important. Anomalies in the tape recorder required NASA engineers to rework how the satellite captured data and what portions of the tape to 


\begin{tabular}{|c|c|c|c|c|}
\hline \multirow[t]{2}{*}{$\begin{array}{l}\frac{5}{0} \\
\text { யํํㅁ }\end{array}$} & $\begin{array}{l}\frac{1980 \text { s }}{\text { Delay in shuttle }} \\
\text { development early } 1980 \\
\text { Hiatus in shuttle launche } \\
\text { after Challenger disaster } \\
\text { CentaurG stage prohibite }\end{array}$ & & $\begin{array}{l}1991 \\
\text { After many years sitting in } \\
\text { storage before launch and use, } \\
\text { high gain antenna malfunctions, } \\
\text { does not open, leaving only the } \\
\text { low gain antenna. }\end{array}$ & $\begin{array}{l}1990 \text { s } \\
\text { Jupiter's harsh radiation } \\
\text { environment plagued } \\
\text { spacecraft. } \\
\text { Tape recorder damage. } \\
\text { Camera/sensor damage. }\end{array}$ \\
\hline & & $\begin{array}{l}\text { 윯 } \\
\text { 트 }\end{array}$ & il $\begin{array}{l}\text { Decreased } \\
\text { communication } \\
\text { bandwidth }\end{array}$ & $\begin{array}{l}\text { Decreased } \\
\text { recording time }\end{array}$ \\
\hline & $\begin{array}{l}\text { leo planned launch for } \\
-23 \text { in } 1982 \text { and STS-61 } \\
986 \text { - both delayed. } \\
\text { profiled w/ gravity assists } \\
\text { und Venus and Earth. }\end{array}$ & 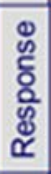 & $\begin{array}{l}\text { Many exercises to open high gain: } \\
\text { thermo cycling. power cycling. spinning } \\
\text { sat and hammering. Re-program on- } \\
\text { board computer to use low gain. Used } \\
\text { DSN and many upgrades to receivers. }\end{array}$ & $\begin{array}{l}\text { Salvaged tape recorder use. } \\
\text { Changed mission CONOPS to } \\
\text { deal with malfunctioned } \\
\text { components. } \\
\text { Developed new mission objectives }\end{array}$ \\
\hline & $\begin{array}{l}\text { sion re-profiling (for } \\
\text { ker upper stage) for } \\
\text { ch slower Jupiter route. } \\
\text { time for development } \\
\text { robe. }\end{array}$ & 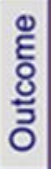 & $\begin{array}{l}\text { Make-shift communications at much } \\
\text { lower speed. } \\
\text { Saved mission from failure using } \\
\text { software, receiver upgrades and DSN }\end{array}$ & $\begin{array}{l}\text { Survived long enough to reach } \\
\text { most mission goals and more. } \\
\text { Saved valuable tape recorder to } \\
\text { store data for slow downlink. }\end{array}$ \\
\hline
\end{tabular}

Figure 9. Galileo Epoch shift-Impact-Response-Outcome Snapshot

safely use. Other issues due to radiation caused more anomalies in the spacecraft that required software and operational modifications. In the end, the Galileo spacecraft was able to remain robust to these context shifts and remained functional throughout its (extended) mission lifetime. The snapshot of these Epoch shift-ImpactResponse-Outcomes can be seen in Fig. 8.

The Epoch shift-Impact—Response-Outcome for this system is one of repeated success. First, the system went through an epoch shift when it was forced to wait on a shelf for years until a new launch could be acquired. This may have resulted in degraded lubricants which ultimately ended up with the high gain antenna malfunctioning. This shift impacted the mission of the spacecraft, limiting the data that Galileo could transmit back to Earth and possibly rendering the satellite useless. The Galileo team responded to this shift by reworking the software and operations of flight and ground segments, as well as upgrading the Deep Space Network. The outcome was a successful primary mission for the satellite. Additionally, the system went through another epoch shift as the radiation environment plagued system components, all requiring custom modifications to software and operations in order to keep Galileo functional during its extended mission.

\section{Insights from the Case Studies}

These cases represent the kind of shifts in contexts that systems must be prepared to face throughout their lifecycle, including development as well as operations. While space systems have unique environments that require special strategies, all systems will require forethought in design to handle these perturbations successfully in their lifespans. Space systems demand this foresight due to severe limitations in the ability to change the system in significant ways once the system is deployed. The construct of Epoch shift-Impact-Response-Outcome is useful in examining these cases to clarify how miscalculations in impact or inappropriate responses may result in failed or successful systems.

Iridium and Globalstar represent how a system that does not appropriately respond to changes in needs can ultimately fail. While Globalstar actually had a response in contrast to Iridium's lack of response, it was still not effective enough to save the company (although it may have had mitigated the full downside consequences of its failure). Both of these systems however live on, operating even today. The continued service of these satellite constellations however should not be considered a success of the original system, but rather the ability of a new company to take advantage of existing capital. These systems had large amounts of investment (both in technology and dollars), and through the mechanism of bankruptcy protection were able to shed their accumulated debts, and could therefore be salvaged to continue to provide value.

Teledesic, while ultimately ceasing operations like Iridium and Globalstar, can be seen as more of a success since it was able to respond to these changes in context and needs and to minimize the downside losses of an unfavorable environment. Teledesic responded to the burst bubble in demand for space-based LEO communication 
satellites and ceased work with relatively little upfront investment compared to Iridium or Globalstar. The Epoch shift-Impact—Response—Outcome construct therefore classifies Teledesic as more of a success.

Interestingly, when considering systems that were actually built and continue delivering value to this day, Globalstar and Iridium might be viewed as a success. In a perverse way, these systems succeeded in responding to their environment, using bankruptcy as a change option ${ }^{1}$. While initial investors lost big money, from the system point of view, bankruptcy allowed the system to shed the downside losses that Teledesic avoided. This could possibly be an actual strategy for getting a system into operations, sacrificing investors' money to end up with an inexpensively acquired system. This strategy, however, comes with risks such as "spoiling the well," and leading to the decrease of investment in all space-based communications, which is what Teledesic suffered from after the bankruptcies of Iridium and Globalstar.

Finally, there is Galileo, a system

Table 1. Epoch shift-Impact-Response-Outcome Summaries

\begin{tabular}{|c|c|c|c|c|c|}
\hline $\begin{array}{l}\text { that was able to } \\
\text { respond to every }\end{array}$ & System & Shift & Impact & Response & Outcome \\
\hline $\begin{array}{l}\text { shift in design, } \\
\text { context or needs and } \\
\text { enable the satellite }\end{array}$ & Iridium & $\begin{array}{c}\text { Cellular } \\
\text { development }\end{array}$ & $\begin{array}{l}\text { Low } \\
\text { subscription }\end{array}$ & None & Failure \\
\hline $\begin{array}{l}\text { to continue to } \\
\text { deliver value. As }\end{array}$ & Iridium & $\begin{array}{l}\text { Increased } \\
\text { communications }\end{array}$ & $\begin{array}{l}\text { More data } \\
\text { demand }\end{array}$ & $\begin{array}{c}\text { Bankruptcy/ Target } \\
\text { niche markets }\end{array}$ & Success \\
\hline $\begin{array}{l}\text { the satellite was } \\
\text { forced into new, }\end{array}$ & Globalstar & $\begin{array}{c}\text { Cellular } \\
\text { development }\end{array}$ & $\begin{array}{l}\text { Low } \\
\text { subscription }\end{array}$ & $\begin{array}{l}\text { Cheaper } \\
\text { architecture }\end{array}$ & Failure \\
\hline $\begin{array}{l}\text { unpredicted } \\
\text { contexts, the system } \\
\text { was able to be be }\end{array}$ & Globalstar & $\begin{array}{c}\text { Increased } \\
\text { communications }\end{array}$ & $\begin{array}{l}\text { More data } \\
\text { demand }\end{array}$ & $\begin{array}{c}\text { Bankruptcy/ Target } \\
\text { niche markets }\end{array}$ & Success \\
\hline $\begin{array}{lr}\text { changed } & \text { to } \\
\text { capitalize on these }\end{array}$ & Teledesic & $\begin{array}{c}\text { Terrestrial data } \\
\text { development }\end{array}$ & $\begin{array}{l}\text { Decreased } \\
\text { demand }\end{array}$ & Scaled down & $\begin{array}{l}\text { Failure/ } \\
\text { Success }\end{array}$ \\
\hline $\begin{array}{l}\text { shifts to meet most } \\
\text { initial science } \\
\text { objectives and even }\end{array}$ & Teledesic & $\begin{array}{l}\text { Iridium/ Globalstar } \\
\text { bankruptcies }\end{array}$ & $\begin{array}{l}\text { Decreased } \\
\text { investment }\end{array}$ & Cease work & $\begin{array}{l}\text { Failure/ } \\
\text { Success }\end{array}$ \\
\hline $\begin{array}{ll}\text { to accomplish } & \text { new } \\
\text { objectives. } & \text { The }\end{array}$ & Galileo & $\begin{array}{l}\text { High gain antenna } \\
\text { failure }\end{array}$ & $\begin{array}{l}\text { Decreased } \\
\text { bandwidth }\end{array}$ & Tech/ Ops re-work & Success \\
\hline ystem's ability to & Galileo & $\begin{array}{l}\text { Component } \\
\text { damage }\end{array}$ & $\begin{array}{l}\text { Decreased } \\
\text { performance }\end{array}$ & $\begin{array}{l}\text { Ops/ objective } \\
\text { re-work }\end{array}$ & Success \\
\hline
\end{tabular}

change operations enabled value robustness for the program. Galileo was subjected to shifts in design (failure of high gain antenna deployment) as well as shifts in contexts (new launch and travel route) and needs (new mission objectives as spacecraft passed asteroids and comets) in an effective way that enabled value-delivery across the entire lifespan.

Table 1 shows the summary of Epoch shift-Impact-Response-Outcomes for the four case studies. The summary shows how Iridium and Globalstar failed as initial systems, but ultimately succeeded in system deployment through the use of bankruptcy. Teledesic both succeeded and failed in both epoch shifts since the system was never developed, but large amounts of downside losses were avoided. Success or failure depends on the criteria being used (providing value as a system or providing profits or minimizing losses). Finally, Galileo shows an example of success in response to both epoch shifts.

When discussing the success of this program, often the lifecycle properties called ilities are referenced (e.g. flexibility or evolvability). Ref 16 and Ref 17 attribute much of Galileo's success to its "flexibility" in design. Similarly, Ref 10 would label the Teledesic response and outcome as flexibility, scaling the architecture during system development with increased contextual knowledge. These cases show how the varying responses to epoch shifts may lead to different outcomes in value sustainment. If these non-traditional lifecycle properties, or ilities, are often used to attribute successful qualities in historical systems, they may be useful concepts for designing systems that are capable of value-sustainment ${ }^{1}$ in the future. More cases may be examined using the Epoch Shift - Impact Response - Outcome construct to build upon the understanding of the impact ilities have on the success of historical systems. Due to time constraints, detailed analyses of other space programs to include DirecTV, GPS, SBR, Mars Polar Lander, Milstar, TerreStar, ORBCOMM, and the ISS were not included in this paper. 


\section{Conclusion}

The construct of the Epoch shift-Impact-Response-Outcome is proposed as a way to analyze system responses to dynamic environments. Using a construct similar to Epoch-Era Analysis ${ }^{4}$, system case examples are discussed using the construct as seen in Fig. 3. The figure describes how a system may be operating at an acceptable level of performance in Epoch 1 and then experience an epoch shift. After experiencing this imposed shift in system, context or needs, the system may display some degradation in performance, known as the impact, possibly bringing performance below expectation levels. The system then, in order to recover to an acceptable performance level, may initiate a response, which then results in some outcome for the system.

The comparison between historical cases shows how system stakeholders may use non-traditional methods to design and ultimately field systems better equipped for handling change in uncertain environments. This paper serves as a proof of concept in Epoch Shift - Impact - Response - Outcome, paving the way for future research across more systems' shifts, responses, outcomes and patterns therein. Iridium was a system that failed to initially respond to the changing needs of the world, and consequently went bankrupt, losing billions of dollars. Globalstar, a similar telecommunications satellite constellation system responded by lowering prices as much as possible and making a slightly less expensive system, but ultimately could not reach the appropriate price-point. In a world with growing terrestrial cellular, Globalstar went bankrupt as well. Both of these systems however were purchased and restructured through the benefits of Chapter 11 bankruptcy and still live on today, producing value for their stakeholders. Success of these systems is doubled-sided then, as they were developed, operated and continue to operate, but they used methods that could be considered perverse to achieve ultimate success. Another satellite constellation system, Teledesic, properly adjusted to the changing needs in the world and scaled down in size and complexity, ultimately ceasing work all together, preventing billions in losses for what would have been a very expensive system. This system was more successful in responding to changing environment by minimizing downside losses, but was, in a sense, less successful than Iridium and Globalstar in that the system was never fielded. The comparison between these systems sheds interesting light on how systems can be designed and ultimately fielded via non-traditional methods. The final case looked into the Galileo deep space exploration satellite that experienced some very harsh mission perturbations, yet was able to overcome and produce value for the stakeholders, in some cases more than was expected. When trying to understand what qualities make a system successful, often the concept of ilities is referenced. The ilities, then, are desirable system properties that often contribute to successful systems, and should be better understood and less ambiguous in order to increase the ability to intentionally design them.

\section{Acknowledgments}

The authors gratefully acknowledge funding for this research provided through MIT Systems Engineering Advancement Research Initiative (SEAri, http://seari.mit.edu) and its sponsors.

\section{References}

${ }^{1}$ Beesemyer, J.C., “Empirically Characterizing Evolvability and Changeability in Engineering Systems,” Master of Science Thesis, Aeronautics and Astronautics, MIT, Cambridge, MA, June 2012.

${ }^{2}$ Ross, A.M., and Rhodes, D.H., "Architecting Systems for Value Robustness: Research Motivations and Progress," 2nd Annual IEEE Systems Conference, Montreal, Canada, April 2008.

${ }^{3}$ Ross, A.M., Rhodes, D.H., and Hastings, D.E., "Defining Changeability: Reconciling Flexibility, Adaptability, Scalability, Modifiability, and Robustness for Maintaining Lifecycle Value," Systems Engineering, Vol. 11, No. 3, Fall 2008, pp. 246262.

${ }^{4}$ Ross, A.M., and Rhodes, D.H., "Using Natural Value-Centric Time Scales for Conceptualizing System Timelines through Epoch-Era Analysis.” INCOSE International Symposium 2008, Utrecht, the Netherlands, June 2008.

${ }^{5}$ Mekdeci, B., Ross, A.M., Rhodes, D.H., and Hastings, D.E., "A Taxonomy of Perturbations: Determining the Ways that Systems Lose Value," 6th Annual IEEE Systems Conference, Vancouver, Canada, March 2012.

${ }^{6}$ Richards, M.G., "Multi-Attribute Tradespace Exploration for Survivability,” Ph.D. Dissertation, Engineering Systems Division, MIT, Cambridge, MA, June 2009.

${ }^{7}$ Mekdeci, B., Ross, A.M., Rhodes, D.H., and Hastings, D.E., "Examining Survivability of Systems of Systems," INCOSE International Symposium 2011, Denver, CO, June 2011.

${ }^{8}$ Finkelstein, S. and Sanford, S.H., "Learning from Corporate Mistakes: The Rise and Fall of Iridium," Organizational Dynamics, Vol. 29, No. 2, 2000, pp. 138-148.

${ }^{9}$ Fossa, C.E., Raines, R.A., Gunsch, G.H., and Temple, M.A., An overview of the Iridium low earth orbit (LEO) satellite system. Proceedings of IEEE 1998 National Aerospace and Electronics Conference, (A99-17228 03-01), Dayton, OH, July 1998, pp. 152-159.

12

American Institute of Aeronautics and Astronautics 
${ }^{10}$ de Neufville, R. and Scholtes, S., Flexibility in Engineering Design, MIT Press: Cambridge, MA, 2011.

${ }^{11}$ Ercetin, O., Ball, M.O., and Tassiulas, L., “Next Generation Satellite Systems for Aeronautical Communications,” Int. Journal of Satellite Communications and Networks, Vol. 22, No. 2, March/April 2004, pp. 157-179.

12 de Weck O.L., de Neufville, R., and Chaize, M., "Staged Deployment of Communication Satellite Constellations in Low Earth Orbit.” Journal of Aerospace Computing, Information, and Communication. Vol. 1, March 2004, pp. 119-136.

${ }^{13}$ Puttalsri, K., Malaithong, A., Schroepfer, B., "Will Globalstar meet the same fate as Iridium?” Colorado University. Capstone Papers, URL: http://hdl.handle.net/123456789/249, 31 May 2006.

${ }^{14} \mathrm{Wu}, \mathrm{W} . W .$, "Internet Satellite Challenges," 2010 Second International Conference on Evolving Internet (INTERNET), September 2010, pp. 20-25, 31-35.

${ }^{15}$ Rittenberg, L., and Tregarthen, T., Principles of Microeconomics, Flat World Knowledge, Ch. 13, 2009.

16 Nilchiani, R., "Measuring the Value of Space Systems Flexibility: A Comprehensive Six-element Framework," Ph.D. Dissertation, Aeronautics and Astronautics, MIT, Cambridge, MA, June 2005.

${ }^{17}$ Saleh, J.H., Hastings, D.E., and Newman, D.J., "Flexibility in System Design and Implications for Aerospace Systems,” Acta Astronautica, Vol. 53, No. 12, December 2003, pp. 927-944. 